\title{
Sustainable Electrochemical Decarboxylative Acetoxylation of Aminoacids in Batch and Continuous Flow
}

\author{
Manuel Köckinger, ${ }^{\text {ab }}$ Paul Hanselmann, ${ }^{c}$ Dominique M. Roberge, ${ }^{c}$ Pierro Geotti-Bianchini, ${ }^{c}$ C. Oliver \\ Kappe $^{* a b}$ and David Cantillo*ab

\begin{abstract}
Introduction of acetoxy groups to organic molecules is important for the preparation of many active ingredients and synthetic intermediates. A commonly used and attractive strategy is the oxidative decarboxylation of aliphatic carboxylic acids, which entails the generation of a new $\mathrm{C}(\mathrm{sp} 3)-\mathrm{O}$ bond. This reaction has been traditionally carried out using excess amounts of harmful lead(IV) acetate. A sustainable alternative to stoichiometric oxidants is the Hofer-Moest reaction, which relies in the 2-electron anodic oxidation of the carboxylic acid. However, examples showing electrochemical acetoxylation of amino acids are scarce. Herein we present a general and scalable procedure for the anodic decarboxylative acetoxylation of amino acids in batch and continuous flow mode. The procedure has been applied to the derivatization of several natural and synthetic amino acids, including key intermediates for the synthesis of active pharmaceutical ingredients. Good to excellent yields were obtained in all cases. Transfer of the process from batch to a continuous flow cell signficantly increased reaction throughput and space-time yield, with excellent product yields obtained even in a single-pass. The sustainability of the electrochemical protocol has been examined by evaluating its green metrics. Comparison with the conventional method demonstrates that an electrochemical approach has a significant positive effect on the greenness of the process.
\end{abstract}

\section{INTRODUCTION}

Organic acetates are widespread among natural products, where the acetoxy group typically plays a significant role in their bioactivity. ${ }^{1}$ In fact, decoration of active molecules with acetoxy moieties can improve their biological properties. ${ }^{1,2}$ Not surprisingly, many synthetic and semi-synthetic acetoxycontaining compounds are important active ingredients utilized as pharmaceuticals, ${ }^{3}$ agrochemicals ${ }^{4}$ and other fine chemical end products (Fig. 1). The presence of the acetoxy group in pharmaceuticals often modulates their solubility and pharmacokinetics, optimizing pharmacological and physiochemical properties. ${ }^{5}$ Additionally, organic acetates can also serve as intermediates for the synthesis of more complex scaffolds, due to the ease with which the $\mathrm{C}\left(\mathrm{sp}^{3}\right)$-OAc functional group can be replaced by a range of nucleophiles in Lewis acid catalyzed substitution reactions. ${ }^{6}$

Synthesis of acetates is very often carried out by acetylation of alcohols using $\mathrm{Ac}_{2} \mathrm{O}$ or $\mathrm{AcCl}$. When suitable hydroxyl groups are not available, an alternative approach for the generation of these valuable moieties is the decarboxylative acetoxylation of aliphatic carboxylic acids. This strategy enables facile generation of N,O-acetals from abundant amino acids, in

\footnotetext{
a. Institute of Chemistry, University of Graz, NAWI Graz, Heinrichstrasse 28, 8010 Graz, Austria.Email: oliver.kappe@uni-graz.at, david.cantillo@uni-graz.at.

b. Center for Continuous Flow Synthesis and Processing (CCFLOW), Research Center Pharmaceutical Engineering GmbH (RCPE), Inffeldgasse 13, $8010 \mathrm{Graz}$, Austria.

c. Microreactor Technology, Lonza AG, CH-3930 Visp, Switzerland.

Electronic Supporting Information (SI) available online
}

addition to other useful transformations. Several procedures for the decarboxylative acetoxylation of carboxylic acids have been developed during the past decades, typically relying on the combination of acetate-containing oxidizing reagents and metal catalysts (Fig. 2a).

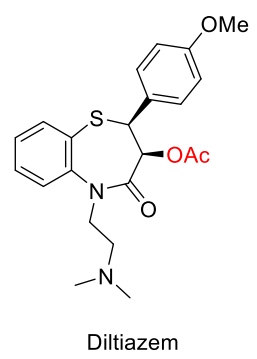

$\left(\mathrm{Ca}^{2+}\right.$ channel blocker)

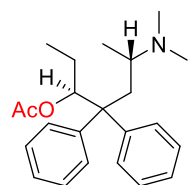

Levacetylmethado (synthetic opiod)

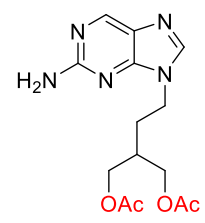

Famciclovir (anti-viral)

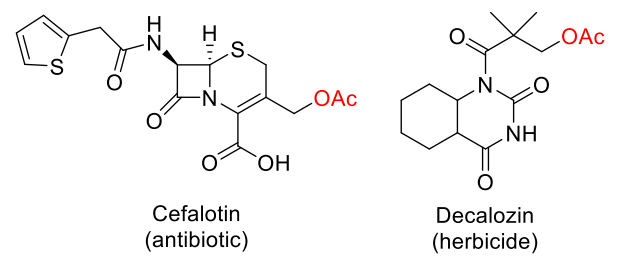

Fig. 1 Examples of active ingredients featuring acetoxy groups 
a) Decarboxylative acetoxylation using conventional reagents

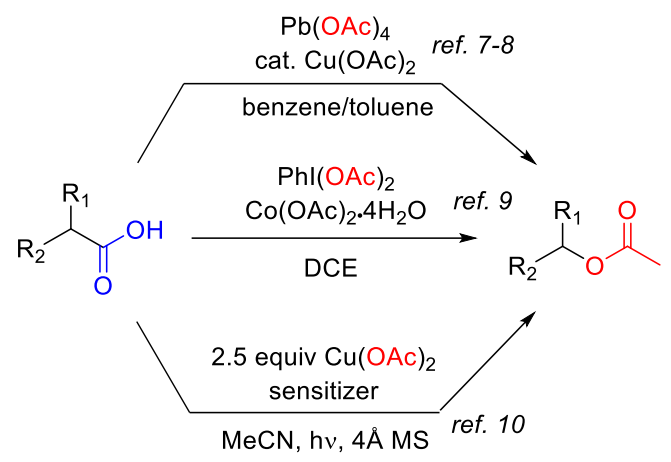

b) Hofer-Moest reaction

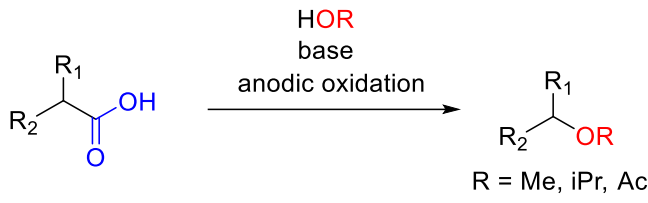

Fig. 2 (a) Synthesis of organic acetates by decarboxylative acetoxylation using conventional reagents and (b) general scheme of the electrochemical Hofer Moest reaction.

The workhorse for decarboxylative functionalization of organic compounds, including acetoxylation, have traditionally been variations of the Kochi reaction, which involves the utilization of excess amounts of $\mathrm{Pb}(\mathrm{OAc})_{4}$ as oxidant, and in some cases $\mathrm{Cu}(\mathrm{II})$ catalysts. ${ }^{7}$ Despite the requirement of stoichiometric amounts of toxic and cancerogenic $\mathrm{Pb}(\mathrm{IV})$ reagents, the Kochi reaction has been employed both in academia and industry for many years. ${ }^{8}$

More recently, some efforts have been devoted to replace $\mathrm{Pb}(\mathrm{OAc})_{4}$ by less harmful reagent alternatives. In this context, $\mathrm{Xu}$ and Tan have described a cobalt catalyzed version of the Kochi reaction, in which $\mathrm{Phl}(\mathrm{OAc})_{2}$ is used as stoichiometric oxidant. ${ }^{9}$ A photochemical method using excess amounts of $\mathrm{Cu}(\mathrm{OAc})_{2}$ has been developed by Tunge and coworkers. ${ }^{10}$ Unfortunately these methods still require the utilization of stoichiometric amounts of metals and oxidants, which results in low atom economy and the generation of large amounts of waste.

The Hofer-Moest reaction is a well-established electrodecarboxylative functionalization of carboxylic acids (Fig. 2a). ${ }^{11}$ In this innately green procedure, 2-electron anodic oxidation of an aliphatic carboxylic acid results in its decarboxylation and the subsequent generation of a carbocation. The carbocation can be trapped by a nucleophile, usually an alcohol that is used as solvent, resulting in the formation of ethers, or undergo rearrangements or eliminations. ${ }^{12}$ This process is closely related to the venerable Kolbe electrolysis, ${ }^{13}$ in which the oxidation stops at the radical stage producing dimers. ${ }^{14}$ The Hofer-Moest reaction has reemerged in recent years, accompanying a general resurgence of electrochemical methods for organic synthesis. ${ }^{15}$ In this context, improved methodologies for the electrochemical preparation of hindered alkyl ethers, ${ }^{16}$ amines, ${ }^{17}$ alkyl fluorides $^{18}$ and cubane functionalization ${ }^{19}$ via variations of the Hofer-Moest reaction have been reported. ${ }^{20}$

Despite this progress, reports on electrochemical decarboxylative acetoxylation have remained relatively rare, possibly due to the lability of some of the electrolysis products. Examples of decarboxylative acetoxylation of amino acids are particularly scarce and limited to a small number of examples. ${ }^{21}$ Due to the importance of $\mathrm{N}, \mathrm{O}$-acetals and the generation of $\mathrm{C}$ $\mathrm{O}$ bonds in the synthesis of bioactive molecules, ${ }^{22}$ we envisioned that the development of a general and scalable electrochemical procedure for the decarboxylative acetoxylation of amino acids would result in a sustainable alternative to the currently employed stoichiometric reagents. For this purpose, the electrochemical reaction was thoroughly optimized and then translated to a single pass continuous flow process. Herein, we report our findings and demonstrate that nearly quantitative yields of the target compounds can be obtained in a single-pass through a flow cell. Furthermore, the sustainability of the process is assessed by benchmarking its green metrics with a standard decarboxylation procedure.

\section{Results and Discussion}

\section{Batch Optimization of the Electrolysis Conditions}

The investigation was initiated with a series of batch experiments aimed to identify an optimal solvent system and reaction temperature, as well as the most suitable electrode materials. All batch optimization reactions were performed under constant current in an undivided cell (IKA Electrasyn $5 \mathrm{~mL}$ vial) using $\mathrm{N}$-phthaloylglycine $\mathbf{1}$ as model substrate. The reaction was initially carried out using acetic acid as solvent, with graphite as the anode and stainless steel as the cathode. Graphite is known to be a good anode material for non-Kolbe electrolysis. ${ }^{23}$ Sodium acetate ( $\mathrm{NaOAc}$ ) was added as base. No additional supporting electrolyte was added to the reaction mixture. In the Hofer-Moest electrolysis, the base utilized (and consequently the basic form of the substrate) is sufficient to provide the necessary conductivity to the reaction solution. Applying a constant current of $20 \mathrm{~mA}$ and $2 \mathrm{~F} / \mathrm{mol}$ of charge $61 \%$ conversion of the starting material and $95 \%$ selectivity toward the target hemiaminal ester $\mathbf{2 a}$ was obtained (Table 1 , entry 1 ). Variable amounts of side product $\mathbf{3}$ were observed in some cases. This compound is formed by cathodic reduction of the carbonyl group and can be favored when proton reduction has a high overpotential. ${ }^{24}$ Mixtures of $\mathrm{AcOH}$ with $\mathrm{MeCN}$, which had been shown as suitable solvents in previous studies, ${ }^{21 a}$ provided significantly reduced selectivity (entries $2-4$ ). In the presence of $\mathrm{MeCN}$, the carbocation was partially trapped by the nitrile, resulting in the formation of the corresponding amide via an electrochemical Ritter-type reaction. ${ }^{25}$ As expected, the amount of the amide side-product increased with larger proportions of $\mathrm{MeCN}$ as co-solvent, thus decreasing the reaction selectivity (entry 2). Increase of the base concentration had a negative effect in the reaction conversion (entries 5-7). As mentioned above, in the Hofer-Moest reaction the base typically deprotonates the carboxylic acid starting material. The 
carboxylate is believed to form a layer at the anode surface. ${ }^{23}$ An excess of acetate would probably compete with the carboxylate in approaching the anode, which explains the reduced conversion with higher base concentrations. Notably, slightly elevated temperatures provided higher current efficiencies (entries 8 and 9). Further increase of the reaction temperature (entry 10 ) resulted in a lower selectivity and at 65 ${ }^{\circ} \mathrm{C}$ (entry 11 ) a complex mixture of side products was formed.

Table 1 Optimization of reaction conditions for electrochemical decarboxylative acetoxylation of $\mathrm{N}$-phthaloylglycine 1 in batch mode.

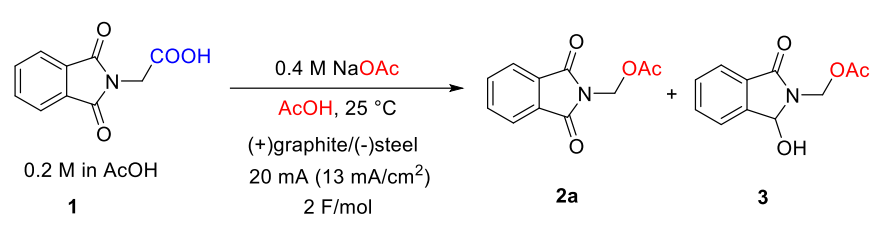

\begin{tabular}{|c|c|c|c|}
\hline & Deviation from above & $\begin{array}{c}\text { Conversion }^{\mathrm{a}} \\
{[\%]}\end{array}$ & $\begin{array}{c}\text { Selectivity }^{\mathbf{a}} \\
{[\%]}\end{array}$ \\
\hline 1 & none & 61 & 95 \\
\hline 2 & $\mathrm{MeCN} / \mathrm{AcOH} 2 / 1$ & 62 & 47 \\
\hline 3 & $\mathrm{MeCN} / \mathrm{AcOH} 1 / 1$ & 64 & 67 \\
\hline 4 & $\mathrm{MeCN} / \mathrm{AcOH} 1 / 2$ & 60 & 73 \\
\hline 5 & $0.6 \mathrm{M} \mathrm{NaOAc}$ & 28 & 95 \\
\hline 6 & $0.8 \mathrm{M} \mathrm{NaOAC}$ & 31 & 95 \\
\hline 7 & $1.0 \mathrm{M} \mathrm{NaOAC}^{\mathrm{b}}$ & 34 & 95 \\
\hline 8 & $35^{\circ} \mathrm{C}$ & 70 & 95 \\
\hline 9 & $45^{\circ} \mathrm{C}$ & 65 & 95 \\
\hline 10 & $55^{\circ} \mathrm{C}$ & 69 & 90 \\
\hline 11 & $65^{\circ} \mathrm{C}$ & 12 & 0 \\
\hline 12 & $30 \mathrm{~mA} / 40^{\circ} \mathrm{C}$ & 61 & 95 \\
\hline 13 & $0.1 \mathrm{M}$ substrate & 37 & 95 \\
\hline 14 & $0.3 \mathrm{M}$ substrate & 48 & 95 \\
\hline 15 & glassy carbon anode & 28 & 99 \\
\hline 16 & $\mathrm{RVC}^{\mathrm{c}}$ anode & 48 & 60 \\
\hline 17 & graphite cathode & 82 & 15 \\
\hline $18^{d}$ & $40^{\circ} \mathrm{C} ; 8 \mathrm{~F} / \mathrm{mol}$ & $>99$ & 95 \\
\hline
\end{tabular}

$0.6 \mathrm{mmol}$ scale. $1.5 \mathrm{~cm}^{2}$ electrode area. ${ }^{a}$ measured by HPLC-UVVIS at $215 \mathrm{~nm}$ bbase not fully dissolved. creticulated vitreous carbon. ${ }^{d}$ 91\% isolated yield.

Surprisingly, the substrate concentration had a significant influence on the reaction efficiency, with $0.2 \mathrm{M}$ being the optimal value (entries 13 and 14). Next, other anode materials were evaluated. Glassy carbon and reticulated vitreous carbon provided lower conversion (entries 15 and 16), demonstrating that graphite is a superior anode material for the reaction. Utilization of graphite as cathode had a negative effect on reaction selectivity (entry 17 ). In this case, reduction of the carbonyl group of the phthaloyl protecting group was favored over proton reduction and compound $\mathbf{3}$ was the major product observed. Finally, using the optimal conditions $(20 \mathrm{~mA}$, graphite/stainless steel, $0.2 \mathrm{M}$ concentration and $40{ }^{\circ} \mathrm{C}$ ) the amount of charge was gradually increased. Full conversion of the starting material and excellent selectivity were obtained after $8 \mathrm{~F} / \mathrm{mol}$ of charge had been applied (entry 18). The excellent conversion and selectivity obtained enabled a simple reaction workup, which consisted of evaporation of the solvent and extraction using EtOAc/aqueous sodium citrate. Product $2 \mathbf{a}$ could be isolated in $91 \%$ yield.

\section{Decarboxylative Acetoxylation Scope}

With the optimal conditions in hand, the scope and applicability of the electrochemical procedure was evaluated. First, a series of phthaloyl protected amino acids was converted to the corresponding acetoxylated analogues (Fig. 3a). In addition to the hemiaminal ester obtained from glycine (2a), other natural hydrophobic side-chain-containing amino acids could be derivatized using the electrochemical protocol. Thus, the acetoxylation products from alanine $(\mathbf{2 b})$, valine $(\mathbf{2 c})$, leucine (2d) and isoleucine (2e) were obtained in good to excellent yields. Aryl-containing phenylalanine and $C$-phenylglycine could also be selectively electrolyzed in good yields ( $\mathbf{2 f}$ and $\mathbf{2 g}$ ). Notably, an extractive workup was sufficient for isolation in many cases, underlining the high selectivity of the process. It should be pointed out that this electrolysis method is not suitable for natural amino acids containing oxidatively labile functional groups such as cysteine.

To further evaluate the functional group compatibility of the anodic decarboxylative acetoxylation procedure, a series of benzyl acetates was prepared from the corresponding aryl acetic acids (Fig. 3b). Such an electrochemical approach and the fact that the acetoxy group can be exchanged with relative ease could lead to a convenient method for the preparation of benzyl-functionalized compounds. Various 2-aryl propionic acids were converted into the corresponding acetoxylated derivatives in very good to excellent yields (4a-d). The method was compatible with the presence of halogens in the aromatic ring. Indeed, nearly quantitative yields were achieved with fluorine (4b) and chlorine (4c) substituents. Diphenyl acetic acid and phenyl cyclopentyl acetic acid also performed well (4e, 4f). Notably, benzal diacetate $(\mathbf{4 g})$ could be prepared from $O$-acetyl mandelic acid in excellent yield. All reactions were carried out using the optimal reaction conditions without modification. The current efficiency was higher for some derivatives and $3 \mathrm{~F} / \mathrm{mol}$ of charge was sufficient in some cases (see Fig. 3 footnote).

The electrochemical protocol for the decarboxylative acetoxylation of amino acids was then applied to more complex building blocks, enabling novel pathways for the synthesis of some active ingredients (Fig. 3c). Intermediate 6, for example, could be obtained in good yield from its carboxylic acid precursor 5, which in turn can be prepared from glycine. Compound 6 can be readily hydrolyzed via aqueous workup. The resulting alcohol is used for the preparation of the potent insecticide tetramethrin. ${ }^{26}$ This preparative method involving electrochemistry in an alternative approach to the Mannich 
(a) Anodic decarboxylative acetoxylation of amino acid derivatives

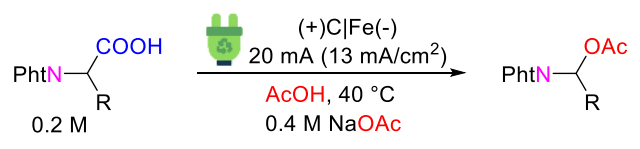<smiles>CC(=O)OCC(Nc1ccccc1)OC(C)C(C)C</smiles>

$$
\text { 2a }(91 \%)^{a} \quad \text { 2b }(99 \%)^{b} \quad \text { 2c }(85 \%)^{\text {b }} \quad \text { 2d }(75 \%)^{\text {b }}
$$

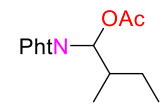

2 e $(90 \%)^{b, d}$

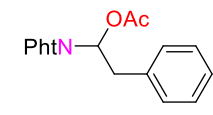

$2 \mathrm{f}(75 \%)^{\mathrm{b}}$

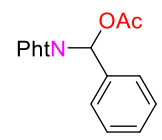

$2 \mathrm{~g}(68 \%)^{\mathrm{b}}$ (b) Anodic benzylic decarboxylative acetoxylation

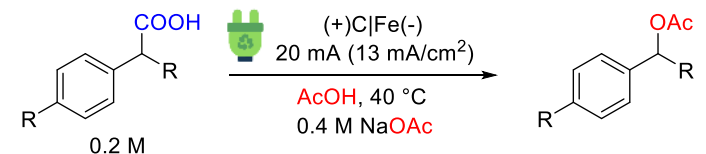<smiles>CC(=O)OC(C)c1ccc(F)cc1</smiles>

4b $(97 \%)^{c}$<smiles>CC(=O)OC(C)c1ccc(Cl)cc1</smiles>

$4 \mathrm{c}(99 \%)^{\mathrm{c}}$

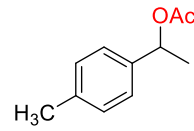

4d $(98 \%)^{\mathrm{C}}$ (c) Generation of API intermediates via anodic decarboxylative acetoxylation of aminoacids<smiles>CC(=O)OC(c1ccccc1)c1ccccc1</smiles>

$4 \mathrm{e}(59 \%)^{\mathrm{c}}$<smiles>CC(=O)OC(c1ccccc1)C1CCCC1</smiles>

4f $(92 \%)^{c}$

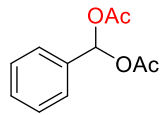

$4 \mathbf{g}(87 \%)^{b}$<smiles>O=C(O)CN1C(=O)C2=C(CCCC2)C1=O</smiles>

5

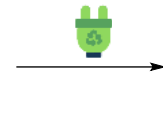

HOOC

7<smiles>Cc1cccc(C(=O)NCC(=O)O)c1</smiles>

9<smiles>O=C1COCCOCCOC(=O)C2CCCCC12</smiles>

$6(63 \%)^{a}$

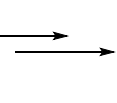

tetramethrin
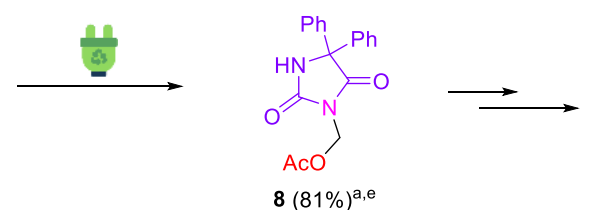<smiles>O=C1NC(c2ccccc2)(c2ccccc2)C(=O)N1COP(=O)(O)O</smiles>

$(+) \mathrm{C} \mid \mathrm{Fe}(-)$

$20 \mathrm{~mA}\left(13 \mathrm{~mA} / \mathrm{cm}^{2}\right)$

$\mathrm{AcOH}, 40^{\circ} \mathrm{C}$ $0.4 \mathrm{M} \mathrm{NaOAC}$

Fig. 3 Scope of the electrochemical decarboxylative acetoxylation of (a) aminoacids (b) benzylic positions and (c) active ingredient intermediates. Isolated yields on a $0.6 \mathrm{mmol}$ scale are shown. ${ }^{\mathrm{a}}$ Reaction completed after $8 \mathrm{~F} / \mathrm{mol}$. ${ }^{\mathrm{b}} 5 \mathrm{~F} / \mathrm{mol}$. ${ }^{\mathrm{c}} 3 \mathrm{~F} / \mathrm{mol}$. d Obtained as mixture of diastereomers. ${ }^{\mathrm{O}} 0.1 \mathrm{M}$ substrate concentration.

reaction typically employed. ${ }^{27}$ Acetoxylated hydantoin 8 was also obtained in very good yield via anodic oxidation of acid $\mathbf{7}$. Notably, this intermediate can be employed for the preparation of fosphenythoin, ${ }^{28}$ a prodrug used to administer the antiepileptic phenythoin. Decarboxylative acetoxylation of amino acid $\mathbf{9}$ yielded $90 \%$ of $\mathbf{1 0}$. Compound $\mathbf{1 0}$ is a viable intermediate for the synthesis of ABT-670, a dopamine agonist. ${ }^{8 b}$

\section{Translation to a Continuous Flow Electrolysis Cell}

Electrochemical reactions rely upon the use of continuous flow electrolysis cells for the scale up to pilot and manufacturing scales. ${ }^{29}$ This is due to the fact that scaling up electrochemical reactions in batch is troublesome. In addition to the mass transfer limitations of batch cells, increasing the size of the vessels has a negative effect on the electrode area to reaction volume ratio. ${ }^{30}$ Moreover, the cell resistance increments as the electrode distance augments in larger electrochemical setups. Flow electrolysis cells, in contrast, can be readily scaled. The small interelectrode distance $(<1 \mathrm{~mm})$ characteristic of flow electrolysis cells ensures high mass transfer efficiency and a very low cell resistance. ${ }^{31}$ Additionally, the electrode area-to- volume ratio is very high and can remain constant during scale up by simply maintaining constant the interelectrode distance. Translation of electroorganic reactions to flow cells, ${ }^{32}$ even initially on a small scale, is therefore essential to ensure that the process can ultimately be scaled up.

Electrochemical reactions in continuous flow cells are often carried out by processing the reaction mixture via recirculation of the electrolyte. ${ }^{29,30}$ Using this strategy, a high conversion of the starting materials can be usually achieved. Gas evolution (e.g. hydrogen formation at the cathode), a significant issue for single-pass processing, is not too problematic, as it is continuously released from the reaction solution reservoir. Electrolyte recirculation is, however, not a truly continuous process, but a semi-batch strategy, as a stream of product solution is not continuously obtained from the setup. ${ }^{32}$ Realization of high yielding single-pass flow electrochemical reactions is highly valuable, as the process can be readily integrated with subsequent synthetic steps.

Prior to attempting the anodic decarboxylative acetoxylation procedure in a continuous flow cell in a singlepass fashion (vide infra), the electrolysis was first evaluated using a recirculation approach (Fig. 4). This preliminary 
evaluation provided valuable information on the electrodes performance and, moreover, a useful procedure for the processing of reaction solutions in a semi-batch approach. All flow electrolysis experiments were carried out in a parallel plate flow cell recently described..$^{33}$ The cell featured an electrode surface contact area of $6.4 \mathrm{~cm}^{2}$ and a channel volume of $190 \mu \mathrm{L}$ ( $0.3 \mathrm{~mm}$ interelectrode distance). As the cell end plates were made of aluminum, it could be easily heated to $40{ }^{\circ} \mathrm{C}$ by simply placing it on a hot plate. The temperature was monitored using a thermocouple inserted between the end plates and one of the electrodes.

Initial attempts were performed using a graphite anode and a stainless steel (AISI 316L) cathode. Electrolysis of methylhippuric acid 9 was utilized as model substrate (Fig. 4), as this is a particularly interesting reaction that is currently carried out using lead acetate as oxidant. ${ }^{8 b}$ A reaction mixture of analogous composition as the batch procedure was prepared on a $5 \mathrm{mmol}$ scale. Recirculation of the reaction mixture was conducted with a syringe pump at a flow rate of $2.5 \mathrm{~mL} / \mathrm{min}$. Although good conversion of the substrate was achieved, a small amount of graphite particles appeared in the reaction mixture as a suspension during the electrolysis. This phenomenon was ascribed to detachment of graphite particles from the anode surface due to the large amounts of $\mathrm{CO}_{2}$ evolved during the oxidation. As graphite is a porous material, the reaction mixture can be partially absorbed into the electrode.

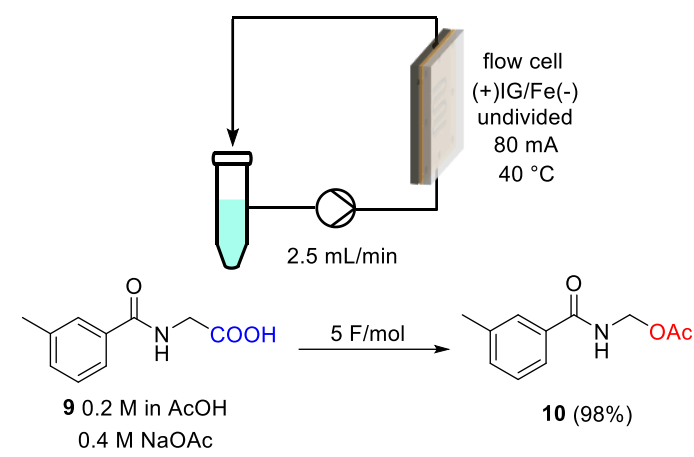

Fig. 4 Electrochemical decarboxylative acetoxylation of methylhippuric acid (9) in a flow cell with recirculation of the electrolyte solution. (+)IG: impervious graphit anode. (-)Fe: stainless steel cathode.

Generation of gas bubbles from within the electrode material can provoke such detachment of particles. Moreover, the graphite anode appeared to soak with the reaction mixture, which might lead to poor residence time distributions and diminished reaction yields. This effect, which can also occur in batch, may be exacerbated by the small pressure drop existing in the flow cell caused by the high flow rates.

To solve the issues observed using standard graphite as the anode material, impervious graphite was evaluated instead. Impervious graphite is a composite material made of ca. $80 \%$ synthetic graphite and $20 \%$ phenolic resin. This material is liquid and gas tight, which avoids the problems of potential leakage of the electrolyte through the electrode. Impervious graphite is commonly utilized in the assembly of fuel cells but it is not typically used in electrolysis. Gratifyingly, with impervious graphite as the anode full conversion of the starting material and excellent selectivity was observed when a current of $80 \mathrm{~mA}$ and a charge of $5 \mathrm{~F} / \mathrm{mol}$ were applied. No particles of graphite were detached from the anode in this case and, importantly, inspection of the electrode revealed that no reaction solution had penetrated the material. Simple workup of the reaction mixture by extraction with EtOAc/sodium citrate yielded $1.02 \mathrm{~g}$ (98\%) of 10 . Notably, this isolated yield is superior to that obtained with the batch cell (91\%).

\section{Single Pass Continuous Flow Electrolysis}

We next turned out attention into developing a single-pass continuous flow procedure. Thus, instead of recirculating the output of the reactor to a solution reservoir, it was collected in a separate vessel (Fig. 5). Impervious graphite was also utilized in this case, and the starting stock solution had the same

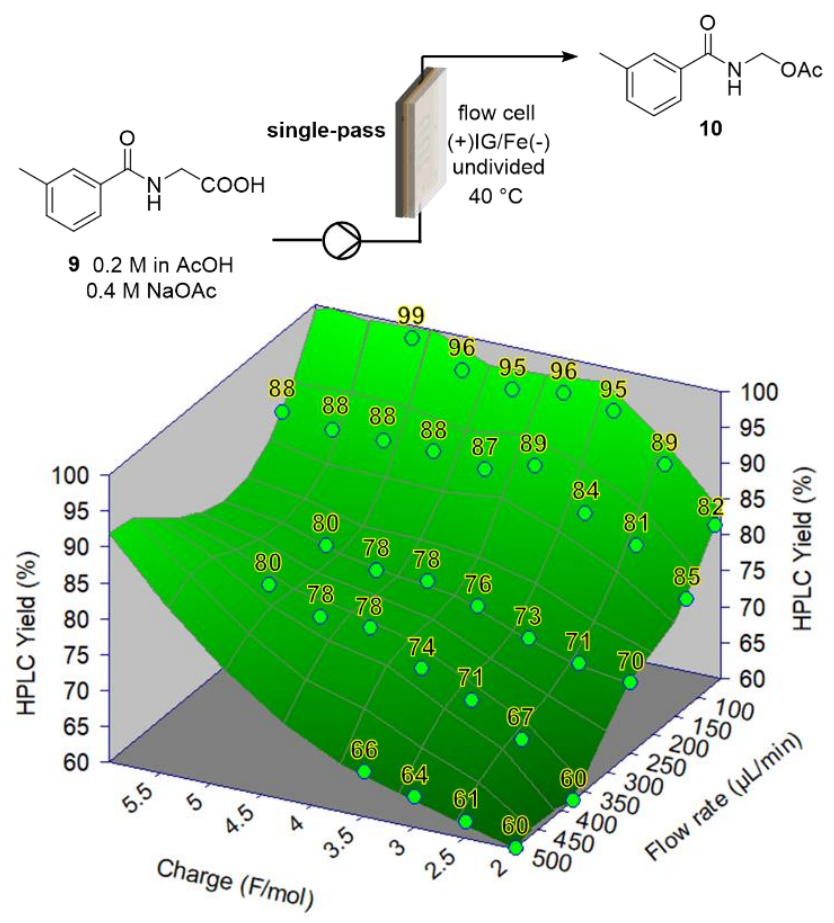

Fig. 5 Optimization of the electrolysis conditions for the single-pass flow decarboxylative acetoxylation of 9 . ( (+)IG: impervious graphite anode. (-) Fe:
stainless steel cathode. Data is collected in Table S1.

composition as in the recirculation experiments $(0.2 \mathrm{M} 9$ in $\mathrm{AcOH}$ with $0.4 \mathrm{M} \mathrm{NaOAc}$ ). One of the advantages of single pass continuous processing using narrow-gap flow cells is that their low volume, and therefore the very low residence time typically used, enables rapid screening of the reaction conditions (Fig. 5). Thus, while the reaction solution was uninterruptedly passed through the cell, the pump flow rate and the cell current were scanned (currents are expressed in $\mathrm{F} / \mathrm{mol}$ in relation to the flow rate; all numerical data is collected in Table $\mathrm{S} 1$ in the Supporting Information). After steady state conditions had been ensured (ca. 3-4 reactor volumes) aliquots of the crude reaction mixture collected from the reactor output were diluted with acetonitrile and analyzed by HPLC. As expected, lower current densities, and thus lower flow rates for a given amount of charge favored high 
conversions. Notably, excellent selectivities (99\%) were observed in all cases. Quantitative conversion of methylhippuric acid (9) to compound $\mathbf{1 0}$ was achieved with a charge of $5 \mathrm{~F} / \mathrm{mol}$ when $100 \mathrm{~mA}$ current and $62 \mu \mathrm{L} / \mathrm{min}$ were applied. The current efficiency achieved was therefore the same as the one obtained with the recirculation approach.

The single pass flow electrochemical reaction showed a very high stability. The reaction could be conducted uninterruptedly for $12 \mathrm{~h}$ with constant outcome. The high selectivity of the reaction again allowed extraction as workup, without the need for chromatographic purification. A yield of $94 \%(8.4 \mathrm{mmol}$, $1.74 \mathrm{~g}$ ) was isolated for the long run experiment. Importantly, the reaction throughput could be increased by more than 5 -fold with respect to batch. The space-time-yield for the single pass electrochemical reaction was approximately 100 times higher than in the small scale batch experiments.

\section{Gas Evolution: Mass Balance and Selectivity Implications}

Large amounts of gas evolution were observed during the anodic decarboxylative acetoxylations described above, both in batch and flow mode. Gas evolution occurs on the cathode $\left(\mathrm{H}_{2}\right.$ gas from the reduction of protons) as well as on the anode $\left(\mathrm{CO}_{2}\right)$. Gas forming electrochemical reactions are often problematic when tackling single-pass electrolysis experiments. In this case, abnormally high amounts of gases were usually observed. This is due to the fact that the reaction solvent $(\mathrm{AcOH})$ can also be electrolyzed, causing the formation of additional amounts of gas $\left(\mathrm{H}_{2}+\mathrm{CO}_{2}+\right.$ ethane). We hypothesized that, at a late stage of the reaction, when the concentration of the starting material is low, the anodic oxidation of $\mathrm{AcOH}$ could in fact become favored. To study this effect, we evaluated the mass balance of reaction mixtures to which increasing amounts
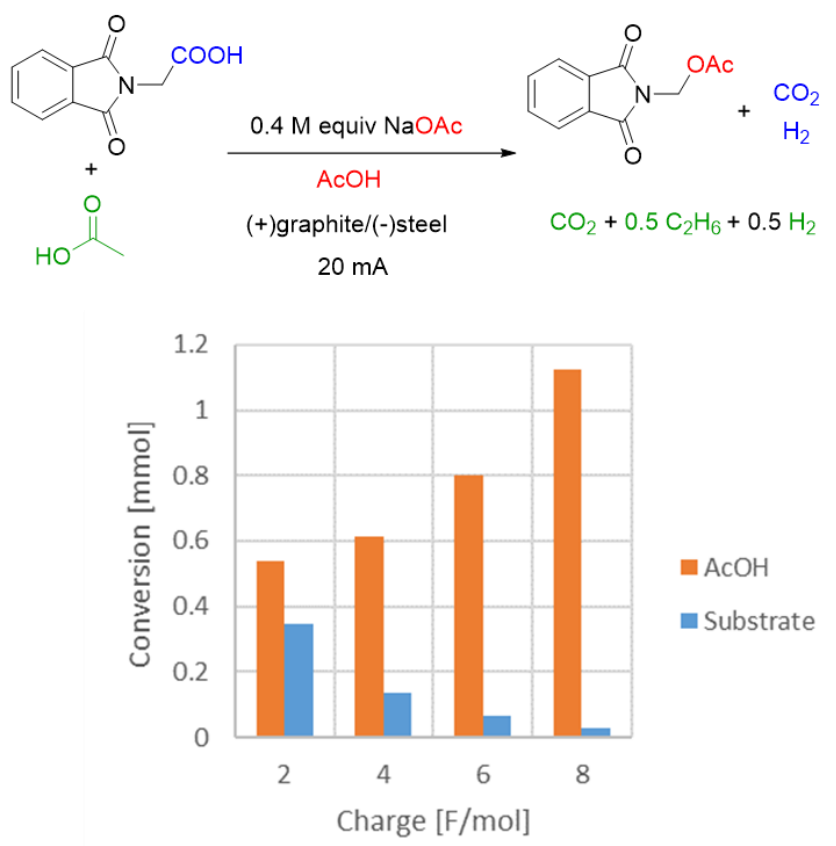

$\mathrm{AcOH}$

- Substrate

Fig. 6 Conversion rates of substrate and $\mathrm{AcOH}$ in a $3 \mathrm{~mL}$ electrolysis cell at a constant current of $20 \mathrm{~mA} / \mathrm{cm}^{2}$. of charge had been applied. For this purpose, amino acid $\mathbf{1}$ was used as model substrate. Combining the mass loss data due to gas evolution with the reaction conversion, we could establish the proportion of substrate (1) and $\mathrm{AcOH}$ that had been oxidized in each step (Fig. 6). Notably, even when 2 F/mol of charge were applied, a large amount of $\mathrm{AcOH}$ appeared to be electrolyzed. As expected, as more charge was applied and the concentration of $\mathbf{1}$ decreased, the amount of solvent electrolyzed increased accordingly. Ultimately, full conversion of 1 , which required $8 \mathrm{~F} / \mathrm{mol}$ in batch, led to the formation of ca. $137 \mathrm{~mL}$ of gas in total.

It should be mentioned that the fact that the solvent can be readily oxidized under analogous conditions as the substrate, ensured that overoxidation reactions (i.e., degradation of the product) did not occur. This phenomenon explains that excellent selectivities were achieved for most reactions.

\section{Process Green Metrics and Sustainability Qualitative Indicators}

Electrochemical methods are considered as "inherently green". ${ }^{34}$ Yet, the substitution of chemical oxidants or reductants by electricity does not guarantee that the resulting process is sustainable. ${ }^{35}$ For this reason, we decided to assess the sustainability of our electrochemical method for the synthesis of the model compound $\mathbf{1 0}$ in terms in green metrics as well as qualitative indicators. They were also compared with those for the literature conventional methodology using $\mathrm{Pb}(\mathrm{OAc})_{4}$ and a copper catalyst. ${ }^{8 \mathrm{~b}, 36}$

Green metrics recommended in the $\mathrm{CHEM} 21$ toolkit ${ }^{37}$ were utilized (Table 2). The formulas and values for the calculation are reported in Tables S2 and S3. Notably, the electrochemical method provided nearly quantitative yield (98\%; electrolyte recirculation mode) while the conventional procedure only yielded $74 \%$ of $\mathbf{1 0}$. The atom economy of the two processes probably caused the most striking difference between the green metrics ( $75 \%$ and $25 \%$ for the electrochemical and conventional procedures, respectively). Unfortunately, no substrate concentration or amounts of solvents were reported in the $\mathrm{Pb}(\mathrm{OAc})_{4}$ procedure. ${ }^{8 \mathrm{~b}}$ Thus, a partial process-mass intensity (PMI) considering only the reactants was compared. Similar to the atom economy, the electrochemical method was clearly superior. The PMI for the electrochemical reaction, including solvent, is $24 .{ }^{38}$ The electrochemical process also outperformed the $\mathrm{Pb}(\mathrm{OAc})_{4}$ procedure in terms of reaction mass efficiency (RME).

Table 2 Green metrics for the electrochemical decarboxylative acetoxylation of methylhippuric acid (9) and comparison with the conventional $\mathrm{Pb}(\mathrm{OAc})_{4}$ process

\begin{tabular}{lcc}
\hline & Recirculation & $\mathrm{Pb}(\mathrm{OAc})_{4}$ \\
\hline Yield & 98 & 74 \\
Atom Economy & 75 & 25 \\
PMI (without solvent) & 1.8 & 4.6 \\
PMI & 24 & - \\
Reaction mass efficiency & 57 & 22 \\
EcoScale & 91 & 61
\end{tabular}


The EcoScale is a semi-quantitative analysis that takes into account ecological and economical parameters. ${ }^{39}$ The maximum score is 100 , and several reaction parameters (yield, use of harmful or expensive chemicals, etc.) "penalize" and subtract points from the total score. The electrochemical process scored an excellent 91 in the EcoScale. The conventional method utilizing stoichiometric reagents scored 61 (Table 2).

One of the most compelling advantages of the electrochemical method is its cost efficiency, especially if the fact that the electrodes can be reutilized for very long periods is taken into account (the impervious graphite electrode was used for many weeks without apparent degradation or fouling). The cost of the electrical power required for the electrochemical reaction, ca. $3 \mathrm{kWh}$ per kilogram of product, is practically insignificant compared to the cost of $\mathrm{Pb}(\mathrm{OAc})_{4}$. Preparation of 1 $\mathrm{kg}$ of material requires $3.2 \mathrm{~kg}$ of $\mathrm{Pb}(\mathrm{OAc})_{4}$. The cost difference difference can be as high as 3 orders of magnitude. Comparison of the costs of all reagents/catalysts involved in the electrochemical and conventional processes, $\mathrm{NaOAc}+$ electricity vs $\mathrm{Pb}(\mathrm{OAc})_{4}+\mathrm{Cu}(\mathrm{OAc})_{2}$, revealed that the cost of the reagents for the lead-based reaction is ca. 50 times higher than for the electrochemical procedure. ${ }^{40}$ This estimation does not consider the cost associated with the management of $\mathrm{Pb}$ contaminated waste.

A comparison of qualitative indicators between the two methods is collected in Table 3 . The assessment of qualitative sustainability is shown by colored flags (green, amber, red), where a green flag stands for "preferred", amber for "is acceptable-some issues" and a red flag is "undesirable". The use of electricity instead of stoichiometric reagents can be assigned with a green flag. The electrochemical reaction operates within the recommended energy efficient temperature window (0$70{ }^{\circ} \mathrm{C}$, green flag), whereas the $\mathrm{Pb}(\mathrm{OAc})_{4}$ reaction uses refluxing toluene $\left(111{ }^{\circ} \mathrm{C}\right.$, amber flag) therefore being less energy efficient. Moreover, the fact that the solvent is heated to reflux

Table 3 Qualitative sustainability indicators for the electrochemical decarboxylative acetoxylation of methylhippuric acid (9) and the conventional $\mathrm{Pb}(\mathrm{OAc})_{4}$ process.

\begin{tabular}{ccc}
\hline & Electrochemical & $\mathrm{Pb}(\mathbf{O A c})_{4}$ \\
\hline Type of reaction & Electricity & Stochiometric Reagent \\
Reactor type & Flow & Batch \\
$\mathrm{T}\left[{ }^{\circ} \mathrm{C}\right]$ & 40 & 111 \\
Reflux & $\mathrm{No}$ & yes \\
Workup & Extraction & Chromatography \\
Solvent & $\mathrm{AcOH}$ & Toluene \\
Health Concerns & $\mathrm{No}$ & H-360Df \\
Environmental & $\mathrm{No}$ & $\mathrm{H}-410$ \\
implications & &
\end{tabular}

grants an additional red flag to the conventional process according to the CHEM21 toolkit. ${ }^{37}$ Other parameters, particularly those regarding environmental and health concern, not surprisingly clearly favor the use of electrochemistry instead of excess amounts of toxic and environmentally unfriendly $\mathrm{Pb}(\mathrm{OAc})_{4}$ and $\mathrm{Cu}(\mathrm{OAc})_{2}$ (Table 3). Importantly, the use of $\mathrm{Pb}(\mathrm{OAc})_{4}$ results in the formation of large amounts of $\mathrm{Pb}$ - containing waste, while in the electrochemical protocol only $\mathrm{H}_{2}$ and $\mathrm{CO}_{2}$ are released as byproducts. $\mathrm{H}_{2}$ can be easily reutilized for, for example, hydrogenations of other scaffold in separate processes, ${ }^{41}$ or for the generation of energy as a fuel. ${ }^{42}$

\section{Conclusion}

We have developed a general, sustainable and scalable electrochemical procedure for the decarboxylative acetoxylation of amino acids and other aliphatic carboxylic acids. Using inexpensive electrode materials, simple electrolysis of the starting material in $\mathrm{AcOH}$ containing $\mathrm{NaOAc}$ as base have provided very good to excellent yield of the target acetoxylated compounds. The electrochemical procedure has been translated to a continuous flow electrochemical cell. Excellent conversion and selectivity has been achieved both in a singlepass processing and with recirculation of the electrolyte. Implementation of impervious graphite as the anode material has enabled stable flow processes and avoided losses of product due to soaking of the electrode with the reaction solution. Under flow conditions, in a flow cell of only $190 \mu \mathrm{L}$ volume, the reaction throughput has been multiplied more than 5 -fold with respect to batch, and the space-time yield increased by two orders of magnitude. Analysis of the green metrics of the electrochemical procedure and its comparison with a conventional method confirmed the remarkable sustainability of this robust protocol.

\section{Conflicts of interest}

The authors declare no competing financial interest.

\section{Acknowledgements}

The CCFLOW project (Austrian Research Promotion Agency FFG No. 862766) is funded through the Austrian COMET Program by the Austrian Federal Ministry of Transport, Innovation and Technology (BMVIT), the Austrian Federal Ministry of Digital and Economic Affairs (BMDW), and the State of Styria (Styrian Funding Agency SFG).

\section{References}

1 Y. Bahrami and C. Franco, Mar. Drugs, 2016, 14, 147.

2 X. Q. Zhang, C. Spadafora, L. M. Pineda, M. G. Ng, J. H. Sun, W. Wang, C. Y. Wang, Y. C. Gu and C. L. Shao, Sci. Rep., 2017, 7, 110.

3 a) G. L. Galiana, A. C. Gauthier and R. H. Mattson, Drugs $R D$, 2017, 17, 329-339. b) W. E. Sneader, in Van Nostrand's Scientific Encyclopedia, John Wiley \& Sons, Inc., Hoboken, NJ, USA, 2007.

4 A. S. Crafts, Modern Weed Control, University of California Press, 2020.

5 D. Jornada, G. dos Santos Fernandes, D. Chiba, T. de Melo, J. dos Santos and M. Chung, Molecules, 2015, 21, 42.

6 a) A. Aliyenne, F. Pin, V. D. Nimbarte, A. M. Lawson, S. Comesse, M. Sanselme, V. Tognetti, L. Joubert and A. Daïch, Eur. J. Org. Chem., 2016, 2016, 3592-3602. b) L. Labanauskas, R. Mazeikaite, R. Striela, O. Gedrimaite, G. Urbelis and A. Zilinskas, Russ. Chem. Bull., 2011, 60, 1672-1676. 
7 a) J. K. Kochi, J. Am. Chem. Soc., 1965, 87, 2500-2502. b) J. K. Kochi and A. Bemis, J. Am. Chem. Soc., 1968, 90, 4038-4051. c) J. D. Bacha and J. K. Kochi, J. Org. Chem., 1968, 33, 83-93.

8 a) US Pat., US20170035906A1, 2017. b) M. V. Patel, T. Kolasa, K. Mortell, M. A. Matulenko, A. A. Hakeem, J. J. Rohde, S. L. Nelson, M. D. Cowart, M. Nakane, L. N. Miller, M. E. Uchic, M. A. Terranova, O. F. El-Kouhen, D. L. Donnelly-Roberts, M. T. Namovic, P. R. Hollingsworth, R. Chang, B. R. Martino, J. M. Wetter, K. C. Marsh, R. Martin, J. F. Darbyshire, G. Gintant, G. C. Hsieh, R. B. Moreland, J. P. Sullivan, J. D. Brioni and A. O. Stewart, J. Med. Chem., 2006, 49, 7450-7465. c) L. Nachbauer and R. Brückner, Eur. J. Org. Chem., 2013, 2013, 6545-6562.

9 K. Xu, Z. Wang, J. Zhang, L. Yu and J. Tan, Org. Lett., 2015, 17 4476-4478.

10 S. Senaweera, K. C. Cartwright and J. A. Tunge, J. Org. Chem., 2019, 84, 12553-12561.

11 H. Hofer and M. Moest, Justus Liebigs Ann. Chem., 1902, 323, 284-323.

12 a) J. P. Coleman, R. Lines, J. H. P. Utley and B. C. L. Weedon, J. Chem. Soc. Perkin Trans. 2, 1974, 0, 1064-1069. b) E. J. Corey, N. L. bauld, J. Casanova and E. T. Kaiser, J. Am. Chem. Soc., 1960, 82, 2645-2646.

13 H. Kolbe, Justus Liebigs Ann. Chem., 1849, 69, 257-294.

14 a) F. Fichter, Organische Elektrochemie, T. Steinkopff, 1942. b) W. J. Koehl, J. Am. Chem. Soc., 1964, 86, 4686-4690. c) A. K. Vijh and B. E. Conway, Chem. Rev., 1967, 67, 623-664.

15 a) M. Yan, Y. Kawamata and P. S. Baran, Chem. Rev., 2017, 117, 13230-13319. b) P. G. Echeverria, D. Delbrayelle, A. Letort, F. Nomertin, M. Perez, L. Petit, Aldrichim. Acta 2018, 51, 3-19. c) A Wiebe, T. Gieshoff, S. Möhle, E. Rodrigo, M. Zirbes and S. R. Waldvogel, Angew. Chem. Int. Ed., 2018, 57, 5594-5619.

16 J. Xiang, M. Shang, Y. Kawamata, H. Lundberg, S. H. Reisberg, M. Chen, P. Mykhailiuk, G. Beutner, M. R. Collins, A. Davies, M. Del Bel, G. M. Gallego, J. E. Spangler, J. Starr, S. Yang, D. G. Blackmond and P. S. Baran, Nature, 2019, 573, 398-402.

17 T. Sheng, H.-J. Zhang, M. Shang, C. He, J. C. Vantourout and P. S. Baran, Org. Lett., 2020, 22, 7594-7598.

18 M. Berger, J. D. Herszman, Y. Kurimoto, Y. Kurimoto, G. H. M. De Kruijff, A. Schüll, A. Schüll, S. Ruf and S. R. Waldvogel, Chem. Sci., 2020, 11, 6053-6057.

19 D. E. Collin, A. A. Folgueiras-Amador, D. Pletcher, M. E. Light, B. Linclau and R. C. D. Brown, Chem. Eur. J., 2020, 26, 374-378.

20 For a recent review on electrochemical decarboxylative transformations, see: V. Ramadoss, Y. Zheng, X. Shao, L. Tian, Y. Wang, Chem. Eur. J. [doi: 10.1002/chem.202001764].

21 a) P. Renaud and D. Seebach, Angew. Chem. Int. Ed. 1986, 25, 843-844. b) D. Seebach, R. Charczuk, C. Gerber, P. Renaud, H. Berner and H. Schneider, Helv. Chim. Acta, 1989, 72, 401-425. c) M. Mori, K. Kagechika, K. Tohjima and M. Shibasaki, Tetrahedron Lett., 1988, 29, 1409-1412.

22 a) M. Rahman, A. Mukherjee, I. S. Kovalev, D. S. Kopchuk, G. V. Zyryanov, M. V. Tsurkan, A. Majee, B. C. Ranu, V. N. Charushin, O. N. Chupakhin and S. Santra, Adv. Synth. Catal., 2019, 361, 2161-2214. b) G. Evano, J. Wang and A. Nitelet, Org. Chem. Front., 2017, 4, 2480-2499. c) S. Mondal and S. Chowdhury, Adv. Synth. Catal., 2018, 360, 1884-1912.

23 H. J. Schaefer, Top. Curr. Chem., 1990, 152, 91-151.

24 M. O. F. Goulart and H. Y. Schäfer, J. Braz. Chem. Soc., 1999, 10, 153-162.

25 L. Eberson, K. Nyberg, K. Ekbom and B. Borgström, Acta Chem Scand., 1964, 18, 1567-1568.

26 Tetramethrin http://sitem.herts.ac.uk/aeru/ppdb/en/Reports/628.htm, (accessed 9 November 2020).

27 Y. P. Volkov and N. F. Shugal, Pharm. Chem. J., 1969, 3, 147-149.

28 Drug Information Portal - U.S. National Library of Medicine Quick Access to Quality Drug Information, https://druginfo.nlm.nih.gov/drugportal/name/fosphenytoin, (accessed 9 November 2020).

29 D. Pletcher and F. C. Walsh, Industrial Electrochemistry, Springer Netherlands, 1993.

30 D. Pletcher, R. A. Green and R. C. D. Brown, Chem. Rev., 2018, 118, 4573-4591.

31 a) T. Noël, Y. Cao and G. Laudadio, Acc. Chem. Res., 2019, 52, 2858-2869. b) M. Elsherbini and T. Wirth, Acc. Chem. Res., 2019, 52, 3287-3296. d) K. Watts, A. Baker and T. Wirth, J. Flow Chem., 2014, 4, 2-11.

32 S. Maljuric, W. Jud, C. O. Kappe and D. Cantillo, J. Flow Chem., 2020, 10, 181-190.

33 W. Jud, C. O. Kappe and D. Cantillo, Chemistry-Methods, 2021, 1, 36-41

34 a) H. J. Schäfer, CR Chim., 2011, 14, 745-765. b) B. A. FrontanaUribe, R. D. Little, J. G. Ibanez, A. Palma and R. VasquezMedrano, Green Chem., 2010, 12, 2099-2119.

35 Y. Yuan and A. Lei, Nat. Commun., 2020, 11, 2018-2020.

36 US Pat., US007528134B2, 2009.

37 C. R. McElroy, A. Constantinou, L. C. Jones, L. Summerton and J. H. Clark, Green Chem., 2015, 17, 3111-3121.

38 C. Jiménez-González, P. Poechlauer, Q. B. Broxterman, B.-S Yang, D. am Ende, J. Baird, C. Bertsch, R. E. Hannah, P. Dell'Orco, H. Noorman, S. Yee, R. Reintjens, A. Wells, V. Massonneau and J. Manley, Org. Process Res. Dev., 2011, 15, 900-911.

39 K. Van Aken, L. Strekowski, L. Patiny and L. Strekowski, Beilstein J. Org. Chem., 2006, 2, No. 3. DOI:10.1186/1860-5397-2-3.

40 Costs analysis based on TCl prices as of Dec-1 2020 for sodium acetate $(21 € / 300 \mathrm{~g})$, lead tetraacetate $(420 € / 500 \mathrm{~g})$ and copper acetate monohydrate $(35 € / 500 \mathrm{~g})$. The cost of $3 \mathrm{kWh}$ of electrical power is below $1 €$. Electrochemical method: $58 €$ reagents per $\mathrm{kg}$ of product. $\mathrm{Pb}(\mathrm{OAc})_{4}$ method: $2696 €$ reagents per $\mathrm{kg}$ of product.

41 T. Wu, B. H. Nguyen, M. C. Daugherty and K. D. Moeller, Angew. Chem. Int. Ed. 2019, 58, 3562-3565.

42 N. Aust and A. Kirste, Paired Electrosynthesis, in Encyclopedia of Applied Electrochemistry, (Eds.: G. Kreysa, K. OtaR. F. Savinell). Springer, New York, NY, 2014. 